\title{
The salinity signature of the equatorial Pacific cold tongue as revealed by the satellite SMOS mission
}

\author{
Christophe Maes ${ }^{1,2^{*}}$, Nicolas Reul ${ }^{3}$, David Behringer ${ }^{4}$ and Terence O Kane ${ }^{5}$
}

\begin{abstract}
The space-borne measurements of the SMOS mission reveal for the first time the complete features of the sea surface salinity (SSS) signature at the full scale of the Pacific basin. The SSS field in the equatorial cold tongue is typically found to be larger than 35.1 within a narrow 2 band of latitude that is positioned slightly south of the equator and that stretches across the eastern Pacific basin up to the Galapagos Islands. On the northern edge of the eastern equatorial Pacific this signature results in a very strong horizontal gradient (larger than 2 units over $100 \mathrm{~km}$ ) with the fresh waters of the Panama warm pool. By considering a water density criterion, it can be shown that the cold tongue is characterized by a strong seasonal cycle with a $3 \mathrm{C}$ amplitude in SST where the warm season of February-March contrasts with the cold period extending from September to November. If the present ocean reanalyzes are able to capture these features, then the assimilation of the SMOS data becomes a worthwhile objective in order to depict more accurately the salinity signature of the cold tongue of the tropical Pacific.
\end{abstract}

Keywords: Physical oceanography; Cold tongue; Salinity; Remote sensing data; Pacific ocean

\section{Background}

The classic paradigm of interannual climate variability in the Tropics involves positive feedback of ocean atmosphere interaction, the Pacific cold tongue and the El Nio/Southern Oscillation (ENSO) phenomenon [4, 11]. The Tropical Pacific Ocean features the largest contrast in Sea Surface Temperature (SST) along the equator from the warm pool in the west $(>28 \mathrm{C})$ to the cold tongue in the east $(\sim 20 \mathrm{C})$, near the Galapagos Islands. Ocean atmosphere interactions can amplify SST anomalies of the cold tongue to sustain either a warm or a cold phase of ENSO, or to generate persistent anomalies with important global impacts like drought [10]. Bjerknes proposed a positive feedback mechanism whereby the ocean interacts with the tropical atmosphere (Walker circulation) to reinforce an initial positive SST anomaly in the equatorial eastern Pacific resulting in weaker trade winds further reducing the east west SST gradient and ultimately producing the warm-phase of ENSO. On longer timescales the cold tongue is also expected to play a

\footnotetext{
* Correspondence: Christophe.Maes@ird.fr

'Institut de Recherche pour le Dveloppement (IRD), Laboratoire d Etudes en Gophysique et Ocanographie Spatiales (LEGOS), Toulouse, France

${ }^{2}$ Now at Laboratoire de Physique des Ocans (LPO), IFREMER/CNRS/UBO/IRD, Brest, France

Full list of author information is available at the end of the article
}

critical role in global warming and its recent hiatus $[13,27]$ as well as on inter-hemispheric and inter-basin exchanges of water [29].

The equatorial cold tongue results from the divergence of surface Ekman currents in response to the large-scale southeast trade winds, which brings cool waters through upwelling into the surface layers. As it represents a substantial part of the equatorial band where the ocean gains a large contribution of heat from the atmosphere, nuch attention has been given to various mechanisms involved in the maintenance of the cold tongue. Recently, Moum et al. [19] provide a quantitative assessment of the influence of ocean small scale mixing events occurring on timescales longer than a few weeks on the seasonal cooling of SST. As opposed to the attention given to the western equatorial Pacific where salinity anomalies can significantly influence SST and ENSO (i.e., [22, 33]), the salinity variability has been largely ignored in the eastern Pacific cold tongue. In his pioneering study of the Pacific equatorial upwelling by means of a simple box model Wyrtki [32] underlined the difficulty of closing the salt budget due to the presence of a strong north south gradient of salinity near the equator. The recent satellite observations by the ESA Soil Moisture and Ocean Salinity (SMOS) and the 
NASA Aquarius SAC-D missions provide the first space-borne measurement of the sea surface salinity (SSS) with sufficient precision to characterize key land ocean and atmosphere ocean interactions [25]. The large-scale variability of SSS can now be investigated with unprecedented space and time sampling.

The purpose of this study is to investigate the salinity signature of the equatorial cold tongue and to examine its relationships with the SST and the interannual climate variability over the past decade. For this purpose, we use the SMOS estimates of the SSS that we crossvalidate and place in the context of a longer time period by considering in situ observations collected by the Argo floats and two state-of-the-art reanalysis systems that provide ocean fields over the 20012013 period. By isolating the cold tongue by means of a density criterion that takes advantage of high-resolution and concomitant data in temperature and salinity, its variability over the recent decade will be presented and discussed.

\section{Methods}

SMOS is a $6 \mathrm{am} / 6 \mathrm{pm}$ sun synchronous polar orbiting satellite carrying an interferometric radiometer operated at 1.4 $\mathrm{GHz}$ and covering the entire globe with a 3-day repeat sub-cycle. SSS is retrieved from reconstructed brightness temperature images across a swath of $\sim 1000 \mathrm{~km}$ with a nominal spatial resolution of $\sim 43 \mathrm{~km}$. At the SMOS sensor frequency, the captured radiation is emitted from the uppermost $1 \mathrm{~cm}$ and the satellite SSS represents an average salinity estimate for the very near-surface layer of the ocean. For this study, we used the Centre Aval de Traitement des Donnes SMOS (CATDS, www.catds.fr) CNES Expertise Center-Ocean Salinity (CEC-OS) SMOS SSS (IFREMER V02) Level 3 products [24]. These are monthly composites of the swath SSS data for the 2010 2013 period at a resolution of 0.250 .25 . The mean error of the composites is about 0.3 psu in the tropical oceans [25]. Satellite SST data used here are the Group for HighResolution SST (GHRSST) [6] level 4 products. In addition, we used upper ocean salinity between $410 \mathrm{~m}$ depth recorded by Argo floats and provided by the Global Data Assembly Centre CORIOLIS (www.coriolis.eu.org/).

The NCEP reanalysis used in this study is an updated version of the operational Global Ocean Data Assimilation System (GODAS) [2, 3] and is a component of the NCEP Climate Forecast System, version 2 [28]. In the present context the GODAS was run in an uncoupled mode, forced by surface fluxes from the NCEP-DOE Reanalysis 2 [12] and augmented by relaxation at the surface to the Reynolds daily SST product [26] and an NODC SSS climatology. The analysis uses a 3D variational method that assimilates temperature and salinity profiles from the Argo array, XBTs, and the moored TAO, TRITON, PIRATA and RAMA tropical buoys.
The CSIRO reanalysis is based on the Australian Community Climate Earth System Simulator-Ocean (ACCESS-O) configuration of the GFDL MOM4p1 ocean-ice code [5]. The ocean model configuration and data assimilation scheme are as described in Maes and O Kane [17]. The model is integrated with a modified variant of ensemble optimal interpolation data assimilation system [20], including 432 monthly mean anomaly ensemble members, to produce an ocean reanalysis for the period 19902007 [21]. The reanalyses described in this study employ atmospheric fields from the CORE.v2 interannually varying forcing and consider a 14-day window of observations and cycle for reanalyses that include only temperature and salinity profile observations from XBT, CTD and Argo and satellite SST. SSS restoring is included but as satellite SST is assimilated no SST restoring is done.

\section{Results and discussion}

The annual average SST field in the tropical Pacific Ocean for the period 20102013 as derived from the SMOS data is shown in Figure 1a. The upwelling of cold subsurface waters stretches along the equator from the coast to near the dateline. The cold tongue is largely contained in the region bounded by $3.5 \mathrm{~N}$ and $3.5 \mathrm{~S}$ and extending from the Galapagos Islands (around 0-90W) to the dateline, hereafter referred to as the Wyrtki box [32]. The cold tongue is also characterized by surface waters with the greatest density in the equatorial zone, typically more than $22.5 \mathrm{~kg} / \mathrm{m}^{3}$, that marks the eastern limit of the western Pacific warm pool [15, 22, 23]. Figure 1b displays the correponding SSS field derived from the SMOS observations and averaged over the same period. North of the equator, between $4 \mathrm{~N}$ and $10 \mathrm{~N}$, low salinity tropical surface water extends across the Pacific and coincides with a region of the InterTropical Convergence Zone (ITCZ) where, in the mean, precipitation exceeds evaporation. The lowest salinity values are observed in the far eastern Pacific Ocean within a pool of water bounded by strong fronts [1]. In the Southern Hemisphere, the process is reversed with evaporation exceeding precipitation, and consequently the SSS values are greater than 35 , with the largest values observed in the central part of the subtropical gyre. In the southwest Pacific Ocean, low values of SSS indicate the presence of the South Pacific Convergence Zone that originates over the Solomon Islands (around 155E).

Along the equator and slightly south of it, the SMOS data show persistent very high SSS values, typically larger than 35.1, with an extent that precisely coincides with the cold tongue. In comparison to the standard climatology the boundary between the equatorial waters and the northern fresh waters is slightly north of the equator, in agreement with the evidence from surface 


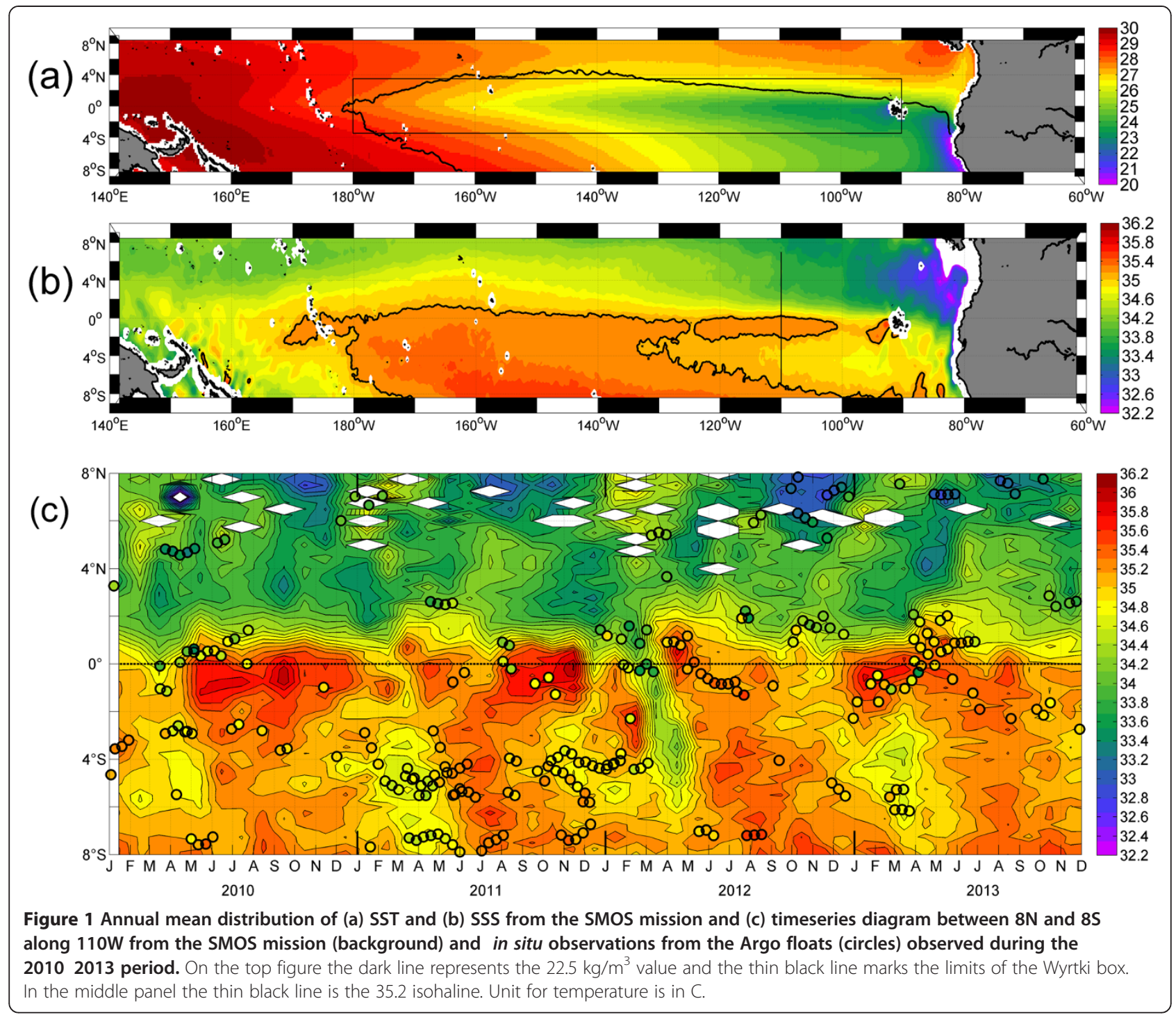

nutrient concentrations and chlorophyll-a pigments [7]. It is likely that this SSS signal is the salinity signature of the upwelled waters along the equator. Because trains of large amplitude vortices as well as tropical instability waves could generate intense horizontal convergence and divergence of the flow and thus influence the SSS field in the region $[8,14]$, it is important to analyze with more accuracy the SSS variability observed in the core of the cold tongue. Other sources of potential errors originating from the retrieval of the SMOS observations will be discussed later. Figure 1c shows a timeseries of the satellite SSS between $8 \mathrm{~N}$ and $8 \mathrm{~S}$ at 110W (along one of the standard longitude of TAO/TRITON array). It shows the persistence of salty waters to the north, with the exception of an intrusion south of the equator of fresh water in February-March 2012 that is corroborated by the Argo in situ observations. In the band from the equator to $2 \mathrm{~S}$ the SMOS measurements are almost always larger than the in situ observations, resulting in a positive bias around 0.1-0.15 from a statistical point of view (see Additional file 1). It should be remembered that these two data sets have significant differences in terms of space and time sampling. The influence from high frequency and small-scale processes could result in differences between these two types of products that are larger than 1 unit, similar to what was reported by Maes et al. [16] and Vinogradova and Ponte [31]. It is obvious in Fig. 1c for instance (see at $1 \mathrm{~S}$ during the first half of 2013) that Argo SSS observations that are very close in time and space could differ significantly. Another key dissimilarity between these two data sets is the difference sampling depths that could be as much as several meters and so generate significant contrasts in tropical regions [9].

Concurrent satellite observations of SST and SSS at comparable sampling rates and global coverages allow us 
to map the surface density of waters. Along the equatorial Pacific the upwelled waters are cold and salty and are therefore dense. We use a density-based criterion to identify the water of the cold tongue and to define an equatorial upwelling index within the Wyrtki box. Figure 2 shows several time series of SST in the Wyrtki box averaged according to several criteria. The black curve represents the SST variability over the full domain. The dashed line shows a similar variability but for waters with density larger than $22.5 \mathrm{~kg} / \mathrm{m}^{3}$ and, as expected, the differences are small as the same water type occupied the full box most of the time. Changes are larger for waters with a density larger than $23 \mathrm{~kg} / \mathrm{m}^{3}$ (light blue curve) with a typical peak to peak amplitude larger than $3 \mathrm{C}$ and a time evolution characterized by the warmest conditions during March-April and the coldest conditions during the Sept-Oct-Nov period of each year. The uncertainties in the SSS $(+/-0.15)$ are represented by the shaded area around the curve and are less than $0.5 \mathrm{C}$ on average. The SST averaged for water with a density greater than $23.25 \mathrm{~kg} / \mathrm{m}^{3}$ shows a more pronounced cooling as expected but with no change in the phase of the seasonal variability in contrast to the average SST of surface waters for the entire cold tongue (defined hereafter as waters for surface density $>23.0 \mathrm{~kg} / \mathrm{m}^{3}$ ).

Although the SMOS data are not presently assimilated by the NCEP climate forecast system, the agreement between the SST variability in the cold tongue (red curve for NCEP in Fig 2) is good and supports the possibility of extending the time period of our study by using the NCEP and CSIRO reanalysis products (Figure 3). Over 2001 2013, the period of the cold tongue variability is relatively stable but there is also a significant interannual variability in the amplitude with a reduction of the maximum cooling during the warm ENSO events of 2002 2003, 20062007 and 2009 2010. There is nevertheless a lot of variability between each event with the strongest positive SST anomalies (greater than 1C) in the cold tongue observed in 2006 whereas the warmest waters in the Wyrtki box were observed during the 20092010 event. The coldest SSTs in the cold tongue were observed during the La Nia periods of 2001, 2007 and 2010. This variability seems to be coherent with the recent trends in ENSO that have been related to an increase in the central Pacific variability [30] but it deserves further analysis that is beyond the scope of the present study.

If the temporal phase of the SST variability of the cold tongue is quite similar between the NCEP and CSIRO products (Fig 3a), differences in amplitude raise the question of the potential role of the SSS to explain them. Note that SST observations are assimilated in both products but many possibilities related to the nature of the SST product and/or the methodology used could lead to substantial differences. However, Figure 3b shows that the main SST differences are also matched by SSS

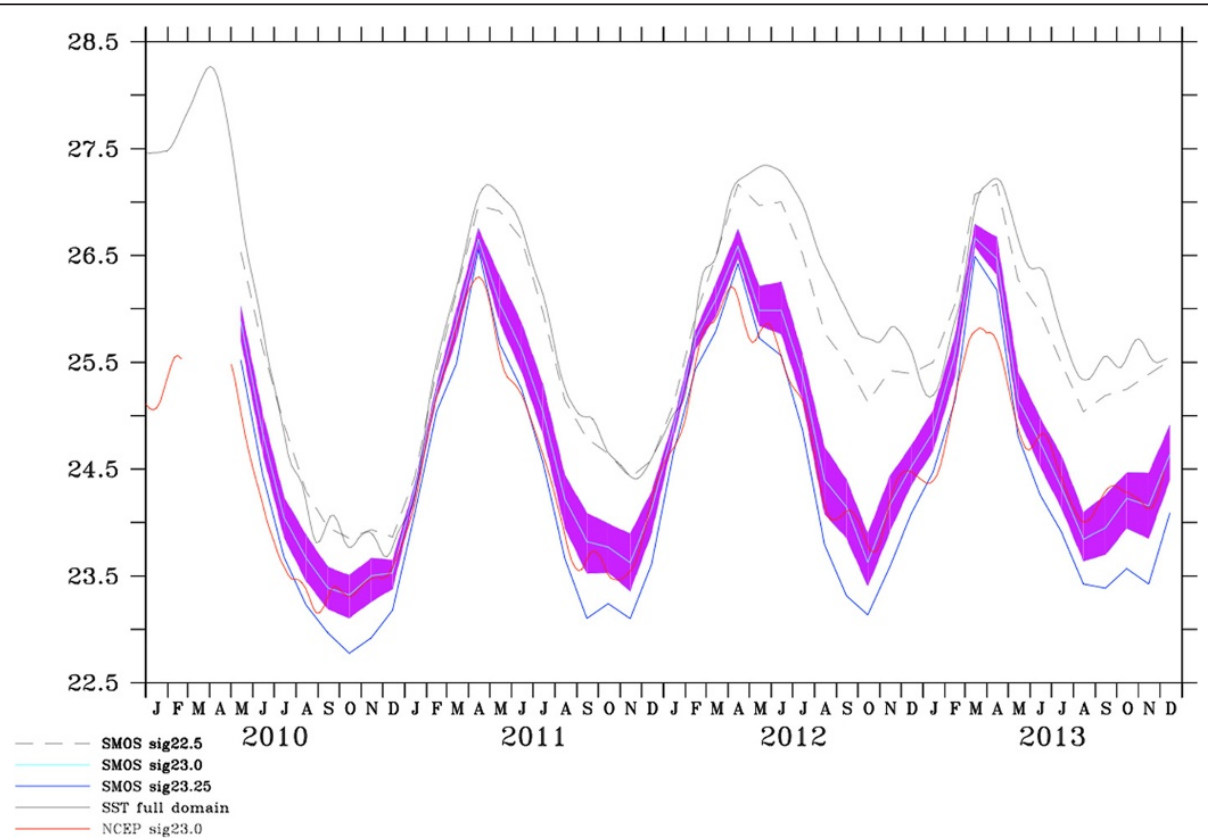

Figure 2 Timeseries of the cold tongue variability as defined as the SST averaged over the Wyrtki box (black). Dash black line represents the SST variations of the waters that are denser than $22.5 \mathrm{~kg} / \mathrm{m}^{3}$, and the light blue and blue lines are respectively the SST variations for a density criterion of 23.0 and $23.25 \mathrm{~kg} / \mathrm{m}^{3}$, respectively. The red curve is derived from the NCEP reanalysis for the 23.0 criterion. The spreading around the light blue curve is obtained by considering a $+/-0.15$ for the SSS field in the determination of the surface density of waters. Unit is in C. 

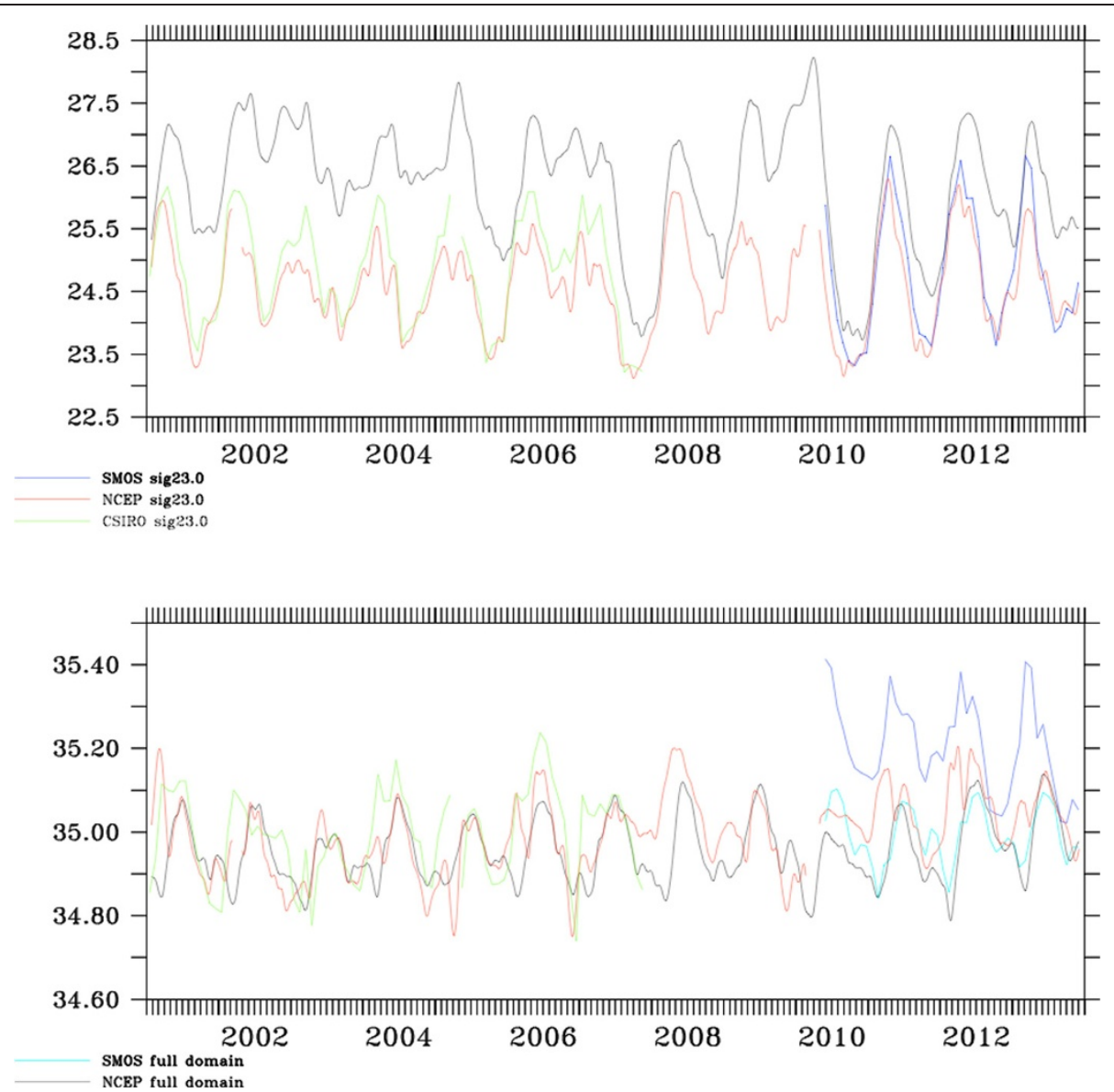

Figure 3 Timeseries of (top) SST and (bottom) SSS fields from NCEP averaged over the Wyrtki box (black lines). For SST the SST variations associated with the waters denser than $23.0 \mathrm{~kg} / \mathrm{m}^{3}$ are superimposed for the SMOS (blue), NCEP (red) and CSIRO (green) analysis. For SSS, the SMOS estimate over the full domain is shown in light blue, the color code remaining unchanged for the other curves and corresponds to the same criterion as shown in the SST part.

differences and the CSIRO SSS amplitude is typically larger during the warm season of the cold tongue variability as compared to NCEP (red and green curves). The recent period shows another interesting result and behavior of the NCEP reanalysis: if the full SSS variability within the Wyrtki box is close to the SMOS observations (light blue curve) the SSS of the cold tongue waters exhibit a substantial low bias (around 0.2) in the NCEP reanalysis, while the phase remains good. In the absence of SSS observations and salinity profiles from the fixed tropical moorings, the present NCEP reanalysis uses synthetic salinity profiles based on local TS correlations combined with a correction term that dampens the SSS to climatology. Both of these methodologies will drive the SSS toward climatology and act to freshen the SSS simulated by the NCEP model. Whether or not this effect could impact the SST simulation of the cold tongue needs to be investigated in more detail.

Observed differences between the monthly mean fields from SMOS and uppermost (typically $5 \mathrm{~m}$ ) Argo observations in the cold tongue might have several sources. SMOS SSS is retrieved from the radiometer data after correcting for geophysical contributions to the measured radiation such as atmospheric effects, external source radiation (sun and galaxy), sea surface roughness, SST, etc. The retrieval algorithm thus requires a priori auxiliary information such as sea surface roughness descriptors (e.g., wind speed) and we use those predicted by the European Centre for Medium-Range Weather Forecasts (ECMWF) operational system. Strong SST gradients, differing atmospheric stability regimes, equatorial current modulation of the sea surface roughness and diurnal variability of the upper ocean associated with sub-grid scale processes in the equatorial cold tongue are known to contribute to significant biases in such descriptors from the ECMWF system [18]. This may explain partly why SMOS retrieved SSS is observed to be in general saltier $(+0.1$ to +0.2$)$ than in situ observations along the equator.

Presently, the large uncertainty in estimates of the magnitude of freshwater exchanges between the ocean 
and atmosphere prevents a precise closure of the coupled water budget at global scales. A greater effort should be undertaken to analyze the fidelity of, and improve the depiction of, processes involved in coupled climate models and assimilation systems. In the tropics, regions characterized by abrupt and short scales of variability, spatially and temporally, suggest a potential advantage to damping the SSS toward the SMOS data rather than toward a climatology. It might be expected that regimes where evaporation or precipitation dominates will benefit from this approach in setting the upper boundary condition for near-surface ocean mixing processes as well as the salinity stratification down to the main pycnocline (i.e., [17]). Further work is needed to better understand the impact that will have such damping strategy and it represents the focus of our current efforts.

\section{Conclusions}

By considering recent satellite observations of SSS derived from the SMOS mission and two different products from state-of-the-art models providing ocean reanalysis, this study investigated the variability of the cold tongue along the equatorial Pacific Ocean. Concurrent observations of SST and SSS, observed for the first time at high-resolution at the scale of the Pacific basin, are used to determine a density criterion and to identify the surface waters that characterize the cold tongue. The most striking feature derived from the SMOS data set is the remarkable persistence of high-salinity values along the equator and to the south of it, in a narrow 2 band of latitude. We believe that this signal represents the salinity signature of the equatorial cold tongue for the eastern Pacific Ocean (i.e. eastward of $140 \mathrm{~W}$ up to the Galapagos Islands).

The present analyses demonstrate that the surface waters of the cold tongue, characterized by a greater density than the surrounding warmer and fresher tropical surface waters, have a strong seasonal variability with amplitude of about $3 \mathrm{C}$ that is warm in February-March and cold in September-November. As the representation of surface salinity in ocean models improves, they should prove to be useful tools for investigating the variability of the cold tongue on ENSO and longer interannual time scales. In the future, accumulation of SMOS high-resolution data will contribute to reveal relationships among SSS, SST, and precipitations at the fine spatial scales, which are potentially associated with long-term climate changes of ENSO and decadal-scale phenomena.

\section{Additional file}

Additional file 1: Statistical comparison between spatially co-localized SMOS monthly averaged SSS data and in situ Argo SSS (delayed mode) observations along (a) 110W, (b) 120W, (c) 130W and (d) $140 \mathrm{~W}$. The width band for the selection is set to 2 around each longitude.
The red curves indicate the bin-averaged SMOS data within 0.2 bin widths of ARGO SSS and the vertical bars indicate 1 standard deviation of SMOS SSS within each bin.

\section{Abbreviations}

ECMWF: European Centre for Medium-Range Weather Forecasts; ENSO: El Nio/Southern oscillation; GODAS: Global Ocean Data Assimilation System; SST: Sea surface temperature; SSS: Sea surface salinity; SMOS: Soil moisture and ocean salinity.

\section{Competing interests}

The authors declare that they have no competing interests.

\section{Authors contributions}

CM carried out the cold tongue analysis using the different products and drafted the manuscript. NR provides the SMOS SSS analyses whereas the model outputs were carried out and jointly analyzed by DB and TK, respectively for the NCEP and CSIRO centers. All the authors read and approved the final manuscript.

\section{Authors informations}

$\mathrm{CM}$ is a research senior at the Institut de Recherche pour le Dveloppement (IRD) and integrates recently the Laboratoire de Physique des Ocans (LPO) in Brittany. The research topics of CM are related to ocean dynamics of the tropical regions with an emphasis on the role of salinity in the upper ocean layers that could have an influence on the ENSO variability. NR is a reserach senior at the Institut Franais de Recherche et d Exploitation de la MER (IFREMER) and a SMOS mission expert. He is responsible for the CNES Expertise Center for Ocean Salinity of the Centre Aval de Traitement des Donnes SMOS. DB is an oceanographer at the National Centers for Environmental Prediction (NCEP), which is part of the National Weather Service (NWS) of the National Oceanic and Atmospheric Administration (NOAA) in Washington, D.C. His area of expertise is the development of ocean data assimilation systems for climate forecasting. TJO is a senior research scientist at CSIRO and an Australian Research Council Future Fellow. He has expertise in both the theory and practical application of ensemble and statistical dynamical methods to prediction and data assimilation.

\section{Acknowledgments}

The Argo data were collected and made freely available by the International Argo Program and the national programs that contribute to it (www.argo.ucsd. edu, argo.jcommops.org). The Argo Program is part of the Global Ocean Observing System. TJO is supported by an Australian Research Council Future Fellowship and the Australian Climate Change Program.

\section{Author details}

${ }^{1}$ Institut de Recherche pour le Dveloppement (IRD), Laboratoire d Etudes en Gophysique et Ocanographie Spatiales (LEGOS), Toulouse, France. ${ }^{2}$ Now at Laboratoire de Physique des Ocans (LPO), IFREMER/CNRS/UBO/IRD, Brest, France. ${ }^{3}$ Institut Franais de Recherche et d Exploitation de la Mer (IFREMER), Laboratoire d Ocanographie Spatiale (LOS), Toulon, France. ${ }^{4}$ NOAA/NWS/ NCEP, NOAA Center for Weather and Climate Prediction, College Park, Maryland 20740, USA. ${ }^{5}$ CSIRO Oceans and Atmosphere, Box 1538, Hobart, Tasmania 7001, Australia.

Received: 2 September 2014 Accepted: 28 November 2014 Published online: 31 December 2014

\section{References}

1. Alory G, Maes C, Delcroix T, Reul N, Illig S: Seasonal dynamics of sea surface salinity off Panama: The far Eastern Pacific Fresh Pool. J Geophys Res 2012, 117:C04028. doi:10.1029/2011JC007802.

2. Behringer DW, Ji M, Leetmaa A: An improved coupled model for ENSO prediction and implications for ocean initialization. Part I: The ocean data assimilation system. Mon Wea Rev 1998, 126:1013 1021.

3. Behringer DW: The Global Ocean Data Assimilation System at NCEP. $11 \mathrm{~h}$ Symposium on Integrated Observing and Assimilation Systems for Atmosphere, Oceans, and Land Surface, AMS 87th Annual Meeting. San Antonio, Texas: Henry B. Gonzales Convention Center; 2007:12. 
4. Bjerknes J: Atmospheric teleconnections from the equatorial Pacific. Mon Wea Rev 1969, 97:163 172

5. Delworth TL, Broccoli AJ, Rosati A, Stouffer RJ, Balaji V, Beesley JA, Cooke WF, Dixon KW, Dunne J, Dunne KA, Durachta JW, Findell KL, Ginoux P, Gnanadesikan A, Gordon CT, Griffies SM, Gudgel R, Harrison MJ, Held IM, Hemler RS, Horowitz LW, Klein SA, Knutson TR, Kushner PJ, Langenhorst AR, Lee HC, Lin SJ, Lu J, Malyshev SL, Milly PC, et al: GFDLs CM2 global coupled climate models Part 1: Formulation and simulation characteristics. J Clim 2006, 19:643 674 .

6. Donlon CJ, Robinson I, Casey K, Vasquez J, Armstrong E, Gentemann C, May D, Leborgne P, Pioll J, Barton I, Beggs H, Poulter DS, Merchant C, Bingham A, Heinz S, Harris A, Wick G, Emery B, Stuart-Menteth A, Minnett P, Evans B, Llewellyn-Jones D, Mutlow C, Reynolds R, Kawamura H, Rayner N: The Global Ocean Data Assimilation Experiment High-Resolution Sea Surface Temperature Pilot Project. Bull Am Meteorol Soc 2007, 88:1197 1213. doi:10.1175/BAMS-88-8-1197.

7. Fiedler PC, Talley LD: Hydrography of the eastern tropical Pacific: A review. Prog Oceanogr 2006, 69:143 180.

8. Flament P, Kennan SC, Knox RA, Niiler PP, Bernstein RL: The three-dimensional structure of an upper ocean vortex in the tropical Pacific Ocean. Nature 1996, 383:610 613

9. Henocq C, Boutin J, Reverdin G, Petitcolin F, Arnault S, Lattes P: Vertical variability of near-surface salinity in the tropics: Consequences for L-band radiometer calibration and validation. J Atmos Oceanic Technol 2010, 27:192 209. doi:10.1175/2009JTECHO670.1.

10. Hoerling M, Kumar A: The perfect ocean for drought. Science 2003, 299:691 694.

11. Jin FF: Tropical ocean atmosphere interaction, the Pacific cold tongue, and the El Nino Southern Oscillation. Science 1996, 274:76 78.

12. Kanamitsu M, Ebisuzaki W, Woollen J, Yang SK, Hnilo JJ, Fiorino M, Potter GL: NCEP DOE AMIP-II Reanalysis (R-2). Bull Amer Meteor Soc 2002, 83:1631 1643

13. Kosaka Y, Xie X-P: Recent global-warming hiatus tied to equatorial Pacific surface cooling. Nature 2013, 501:403 407.

14. Lee T, Lagerloef G, Gierach MM, Kao H-Y, Yueh S, Dohan K: Aquarius reveals salinity structure of tropical instability waves. Geophys Res Lett 2012 39:L12610. doi:10.1029/2012GL052232.

15. Maes C: On the ocean salinity stratification observed at the eastern edge of the equatorial Pacific warm pool. J Geophys Res 2008, 113. doi:10.1029/2007JC004297.

16. Maes C, Dewitte B, Sudre J, Garon V, Varillon D: Small-scale features of temperature and salinity surface fields in the Coral Sea. $J$ Geophys Res Oceans 2013, 118:5426 5438. doi:10.1002/jgrc.20344.

17. Maes C, O Kane TJ: Seasonal variations of the upper ocean salinity stratification in the tropics. J Geophys Res Oceans 2014, 119:1706 1722. doi:10.1002/2013JC009366.

18. Molteni F, Stockdale T, Balmaseda M, Balsamo G, Buizza R, Ferranti L, Magnusson L, Mogensen K, Palmer T, Vitart F: The new ECMWF seasonal forecast system (System 4). ECMWF Tech Memorand 2011, 656 ECMWF: Reading, UK.

19. Moum JN, Perlin A, Nash JD, McPhaden MJ: Seasonal sea surface cooling in the equatorial Pacific cold tongue controlled by ocean mixing. Nature 2013, 500:64 67

20. Oke PR, Brassington G, Griffin D, Schiller A: The Bluelink Ocean Data Assimilation System (BODAS). Ocean Modelling 2008, 21:46 70

21. Oke PR, Sakov P, Cahill ML, Dunn JR, Fiedler R, Griffin DA, Mansbridge JV, Ridgway KR, Schiller A: Towards a dynamically balanced eddy-resolving ocean reanalysis: BRAN3. Ocean Modell 2013, 67:52 70. doi:10.1016/j. ocemod.2013.03.008.

22. Qu T, Song YT, Maes C: Sea surface salinity and barrier layer variability in the equatorial Pacific as seen from Aquarius and Argo. J Geophys Res Oceans 2014, 119:15 29. doi:10.1002/2013JC009375.

23. Qu T, Yu J-Y: ENSO indices from sea surface salinity observed by Aquarius and Argo. J Oceanogr 2014, 70:367 375. doi:10.1007/s10872-014-0238-4.

24. Reul N, Ifremer CATDS-CECOS Team: SMOS L3 SSS Research Products: Product User Manual Reprocessed Year 2010. Plouzan, France: IFREMER; 2011.

25. Reul N, Fournier S, Boutin J, Hernandez O, Maes C, Chapron B, Alory G, Quilfen Y, Tenerelli J, Morisset S, Kerr Y, Mecklenburg S, Delwart S: Sea Surface Salinity Observations from Space with SMOS satellite: a new tool to better monitor the marine branch of the water cycle. Surv Geophys 2014, 35:681 722. doi:10.1007/s10712-013-9244-0.
26. Reynolds RW, Rayner NA, Smith TM, Stokes DC, Wang W: An improved in situ and satellite SST analysis for climate. J Climate 2002, 15:1609 1625.

27. Risbey J, Lewandowsky S, Langlais C, Monselesan D, O Kane T, Oreskes N: Well-estimated global surface warming in climate projections selected for ENSO phase. Nat Clim Change 2014. doi:10.1038/NCLIMAE2310.

28. Saha S, Nadiga S, Thiaw C, Wang J, Zhang Q, Van den Dool HM, Pan HL, Moorthi S, Behringer D, Stokes D, Pea M, Lord S, White G, Ebisuzaki W, Peng P, Xie P: The NCEP Climate Forecast System. J Clim 2006, 19:3483 3517.

29. Sloyan B, Johnson G, Kessler WS: The Pacific cold tongue: a pathway for interhemispheric exchange. J Phys Oceanogr 2003, 33:1027 1043.

30. Takahashi K, Montecinos A, Goubanova K, Dewitte B: ENSO regimes: Reinterpreting the canonical and Modoki El Nio. Geophys Res Lett 2011, 38:L10704. doi:10.1029/2011GL047364.

31. Vinogradova NT, Ponte RM: Small-Scale Variability in Sea Surface Salinity and Implications for Satellite-Derived Measurements. J Atmos Oceanic Technol 2013, 30:2689 2694.

32. Wyrtki K: An estimate of equatorial upwelling in the Pacific. J Phys Oceanogr 1981, 11:1205 1214.

33. Zheng F, Zhang R-H, Zhu J: Effects of interannual salinity variability on the barrier layer in the western-central equatorial Pacific: a diagnostic analysis from Argo. Adv Atmos Sci 2014, 31:532 542. doi:10.1007/s00376-013-3061-8.

\section{doi:10.1186/s40562-014-0017-5}

Cite this article as: Maes et al:: The salinity signature of the equatorial Pacific cold tongue as revealed by the satellite SMOS mission. Geoscience Letters 2014 1:17.

\section{Submit your manuscript to a SpringerOpen ${ }^{\odot}$ journal and bene $\otimes t$ from:}

- Convenient online submission

- Rigorous peer review

- Immediate publication on acceptance

- Open access: articles freely available online

- High visibility within the 区eld

- Retaining the copyright to your article

Submit your next manuscript at $>$ springeropen.com 